\title{
PUBERTY IN A SEASONALLY BREEDING MALE, THE RED DEER STAG (CERVUS ELAPHUS L.)
}

\author{
G. A. LINGOLN* \\ Department of Veterinary Clinical Studies, University of Cambridge
}

(Received 18th May 1970)

Summary. The changes associated with puberty were studied in thirtyone red deer stags between 3 months and 3 years old. The majority of deer were born in June.

During the first 11 months of life, there was a gradual proliferation of spermatogonia in the seminiferous tubules. From May to October, between 11 and 16 months of age, a marked increase in the size and weight of the testes followed, the content of testosterone also began to rise and spermatogenesis was initiated. Over the same period, the weight of the epididymides, seminal vesicles, ampullae and prostate, and the concentration of seminal fructose increased. The antler pedicles began to develop in May, and antler tissue was evident by August.

The testes and accessory glands reached a peak in activity in October at 16 months of age but the development of the secondary sexual characteristics, including growth of the neck mane and 'stag' winter coat and the cleaning of the antlers, was not completed until 2 to 3 months later. Unlike the adult stags in October, the yearlings showed no rutting behaviour.

Following this peak in development, the testosterone content of the testes quickly declined to a low level, though spermatogenesis continued at a reduced rate through the winter and spring. Over this period, the weights of the accessory glands declined. In June, at 2 years old, spermatogenesis was arrested, the accessory glands were involuted, and the first set of antlers was cast. This marked the end of the first reproductive cycle; the testes and accessory glands redeveloped in October. In this second cycle, the secondary sexual characteristics developed earlier and some aspects of rutting behaviour occurred.

Puberty in the stag was defined as the period from 9 to 15 months of age, from the onset of androgen secretion to the completion of spermatogenesis. These changes were considered similar to the changes which occur each year in the adult in preparation for the breeding season.

\section{INTRODUCTION}

Puberty in the male may be defined as the period when the accessory organs

\footnotetext{
* Present address: Unit of Reproductive Biology, Life Sciences Building, Crown Street, P.O. Box 147, Liverpool L69 3BX.
} 
and secondary sexual characters develop under the influence of the testis (Donovan \& van der Werff ten Bosch, 1965) and the animal first becomes fertile. A seasonal breeder like the red deer stag, which lapses into a state of complete reproductive quiescence each year, might therefore be said to have an annual puberty (Lincoln, 1971). The purpose of this investigation was to see if the initial puberty of the young stag differed from the seasonal puberty of the adult.

\section{MATERIALS AND METHODS}

\section{Animals}

The stags were shot by Nature Conservancy stalkers from a free-ranging population of red deer on the Isle of Rhum National Nature Reserve off the west coast of Scotland (long. $6.20^{\circ} \mathrm{W}$, lat. $57.0^{\circ} \mathrm{N}$ ). By culling two or three juvenile animals at approximately monthly intervals throughout a year, a series of thirtyone stags varying in age from 3 months to nearly 3 years was obtained. In addition, over the same period the body weights were recorded of fifty-four adult stags shot for another study (Lincoln, 1971) and these data were used to calculate a body growth curve.

The age of the stags was estimated on the basis of tooth eruption and wear (Lowe, 1967). It was virtually impossible to sex calves under 1 year old by their appearance at a distance so it was necessary to shoot marked animals whose sex was known. In order to simplify the presentation of results, it was assumed that all the stags in the juvenile series shared a common month of birth in June. All seven animals of known age were born during this month, which is the peak calving season on Rhum.

\section{Collection of specimens}

The neck girth of each stag was measured, and then the rumen, reticulum, omasum, abomasum, and large and small intestines were removed and weighed separately from the carcass. The reproductive tract was taken within $5 \mathrm{hr}$ of death and, after dissection, the individual glands were measured and weighed (Lincoln, 1971). Pieces of these glands were fixed in Bouin's solution for histology and the remaining testicular tissue and the seminal vesicles were sealed in plastic bags and frozen to $-20^{\circ} \mathrm{G}$ for subsequent biochemical analysis. The pituitary gland was removed and weighed, and a photographic record was kept of the antler development.

\section{Laboratory techniques}

The fixed tissues were sectioned at $8 \mu$ and stained with haematoxylin and eosin. All histological measurements were made by taking the mean of twenty observations from different areas of the slide. Testosterone and androstenedione concentrations in the testes were determined by the method of Mann, Rowson, Short \& Skinner (1967) and the seminal fructose levels were measured by the method of Lindner \& Mann (1960). 


\section{RESULTS}

\section{Body growth rate}

Text-figure 1 shows the body weights of eighty-four stags shot between 3 months and 15 years of age. It is apparent that the stags continued to grow for at least the first 7 years of life. As puberty occurred between 9 and 15 months of age (see later), these animals would have become fertile when they had attained little more than one third of the expected mature body weight. The progressive increase in weight following puberty may have important bearings on the time of sexual maturity, and is discussed later.

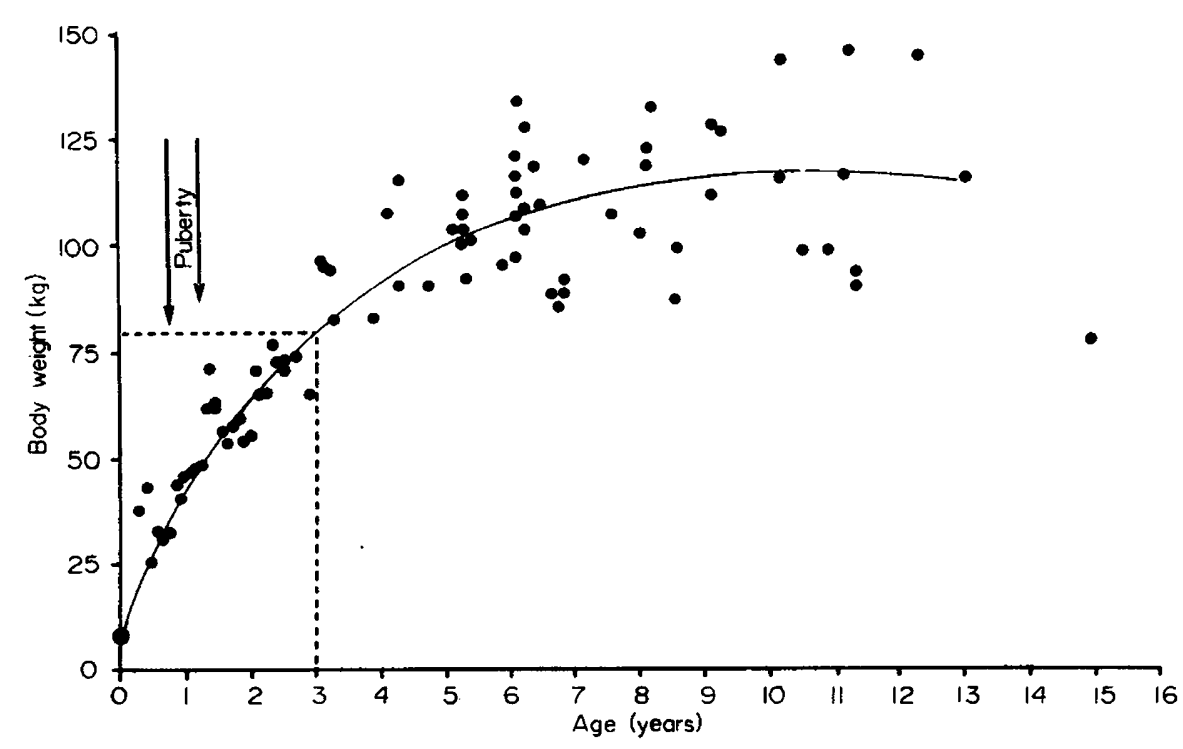

TEXT-FIG. 1. The body weights of eighty-four stags of various ages, showing the relationship between body growth and puberty. The dotted line encloses the body weights of the stags utilized in the main part of this study. The body weight at birth is that obtained in a previous study (Lincoln et al., 1970).

\section{Changes in the testis during the first 3 years of life}

At 3 months of age, in September, the testes of the calf were small (combined weight $3.2 \mathrm{~g}$ ), with solid seminiferous tubules consisting of a peripheral layer of supporting cells and occasional spermatogonia (Pl. 1, Fig. 1). During the following 7 months, there was only a slight increase in testicular weight and seminiferous tubule diameter (Text-fig. 2), but a more obvious increase in the number of spermatogonia (P1. 1, Fig. 2).

Testosterone was first detected in the testes of a 9-month-old calf in March, and the levels found in other deer over the ensuing months tended to show a progressive increase (Text-fig. 3). In May, at 11 months of age, the first primary spermatocytes were seen in a few of the tubules (Pl. 1, Fig. 3), but it was not until August that tubules developed lumina, and the spermatocytes became distributed around the periphery closer to the Sertoli cells. Full spermatogenesis was first seen in September and spermatozoa were packed in the 
epididymis in October at the time when the testicular weight, testosterone content and seminiferous tubule diameter all reached a peak (PI. 1, Fig. 4).

After October, the testes of the yearlings began to regress; the testosterone content decreased almost immediately, while spermatogenesis remained very active in November and December, and then declined until June.

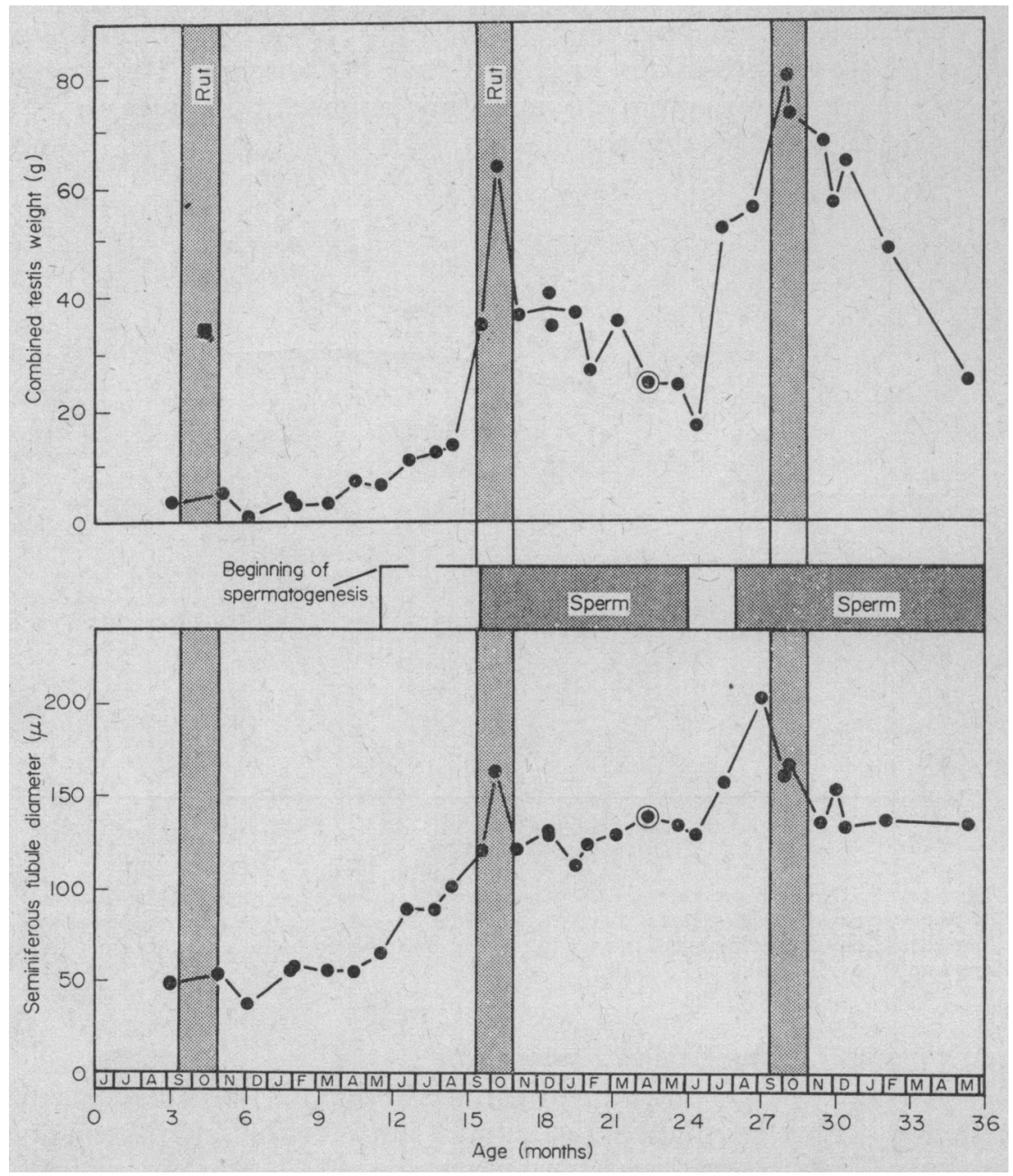

TExT-Fig. 2. The changes in the weight of the testes and diameter of the seminiferous tubules of stags during the first 3 years of life. The encircled symbol was an animal with abnormal testes (see below).

One yearling stag shot in April deserves special mention for it had a very high total content of testosterone in its testes $(78 \mu \mathrm{g})$ at a time when testicular activity might be expected to be minimal. This stag seemed normal except that it had a low combined testis weight due to one gonad being markedly regressed, and much smaller than the other $(8.0$ versus $16.0 \mathrm{~g})$. The data from this stag have been encircled in most figures.

The cessation of spermatogenesis in June at 2 years of age, marked the end of 
the first seasonal cycle of the testis. This coincided with the beginning of the next cycle, for the testosterone content of the testis had already begun to increase again. As before, androgenesis preceded the onset of spermatogenesis, which

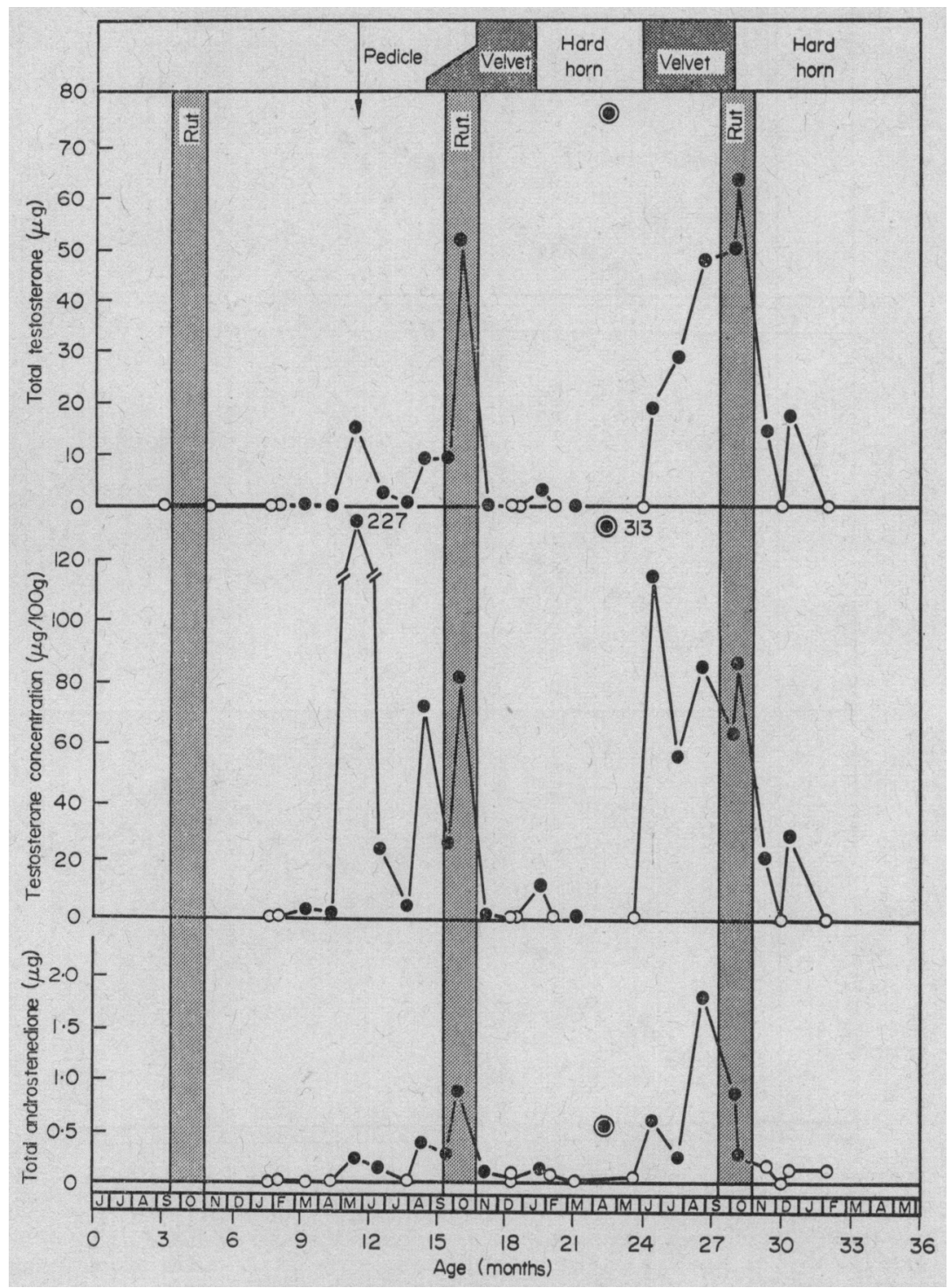

TExT-FIo. 3. The changes in the testosterone concentration and content, and androstenedione content of the testes of stags during the first 3 years of life, and the associated antler development. Open symbols represent $<0.3 \mu \mathrm{g}$ or $<0.03 \mu \mathrm{g} / 100 \mathrm{~g}$.

recommenced in July. The first spermatozoa appeared in August, 2 months earlier than in the first cycle, and testicular activity was again maximal in October during the adult rut.

In the young stags, the androstenedione content of the testes tended to 


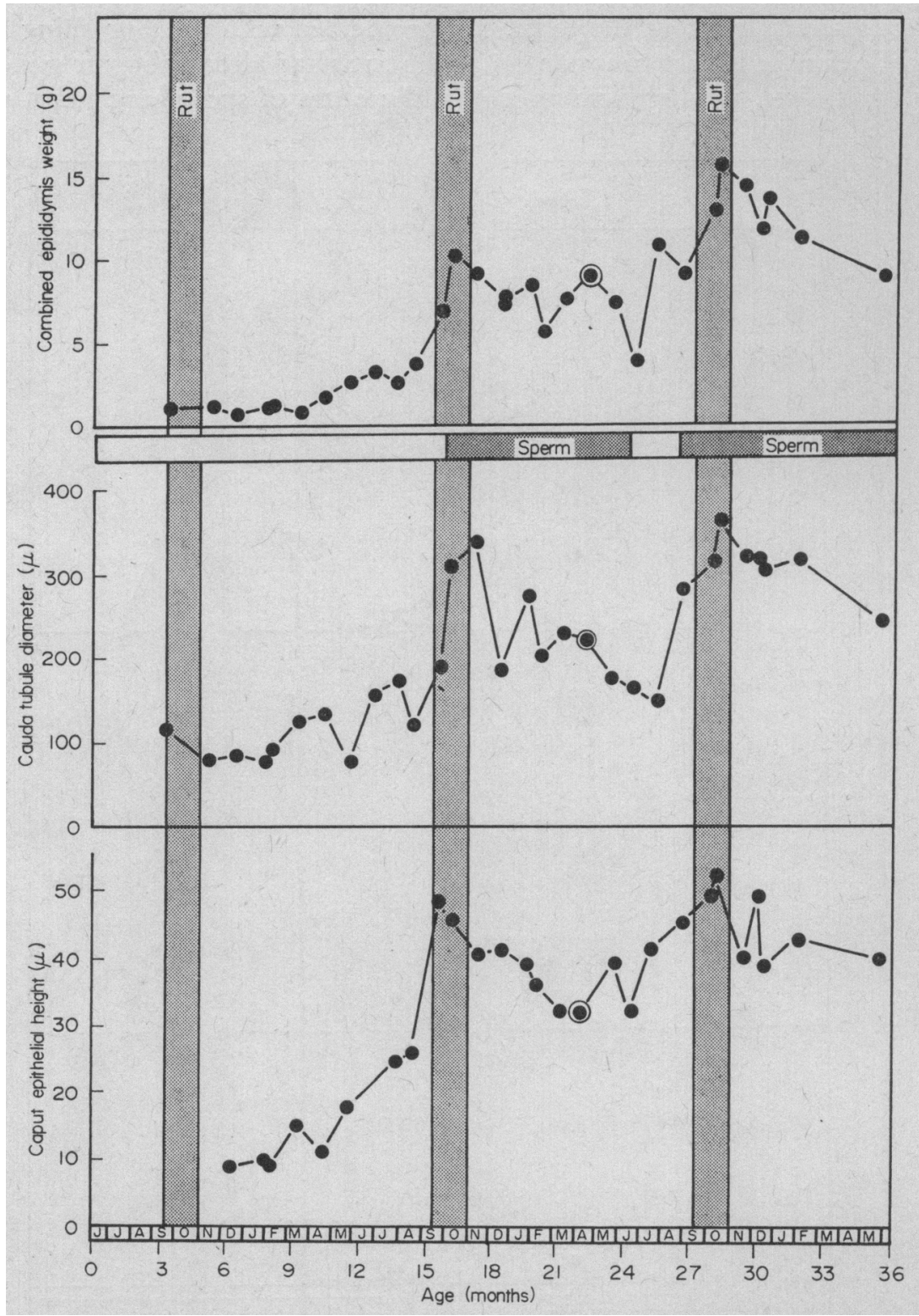

TExT-FIG. 4. The changes in the weight of the epididymides, the epithelial height of the caput epididymides and the diameter of the tubules of the cauda epididymides of stags during the first 3 years of life. For explanation of the encircled symbol see Text-fig. 2 .

\section{EXPLANATION OF PLATE 1}

FIG. 1. Testis of a 3-month-old stag (11/9/68) showing the small, solid seminiferous tubules with a peripheral layer of Sertoli cells and occasional spermatogonia (indicated). $\times 450$. Fic. 2. Testis of an 8-month-old stag (6/2/68) with slightly expanded seminiferous tubules containing clusters of spermatogonia. $\times 450$.

FIg. 3. Testis of an 11-month-old stag (24/5/68) with enlarged seminiferous tubules showing the appearance of the first primary spermatocytes. $\times 450$.

Fig. 4. Testis of a 16-month-old stag (7/10/68) with seminiferous tubules showing all stages of spermatogenesis with maturing spermatids in the lumina. This animal had fully developed pedicles and the first antlers were just beginning to grow in velvet. $\times 450$. 
PL.IIL 1

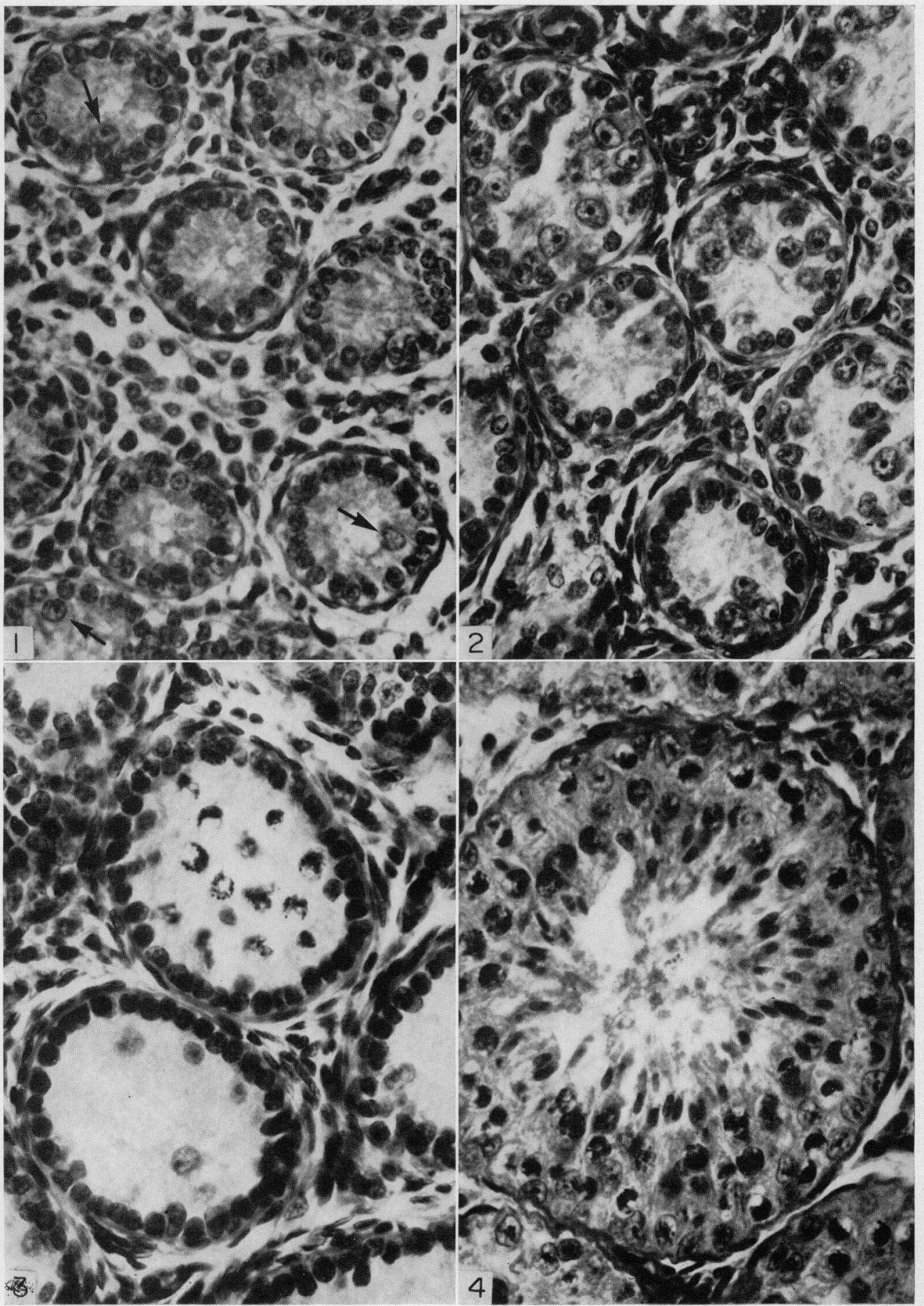


PLATE 2

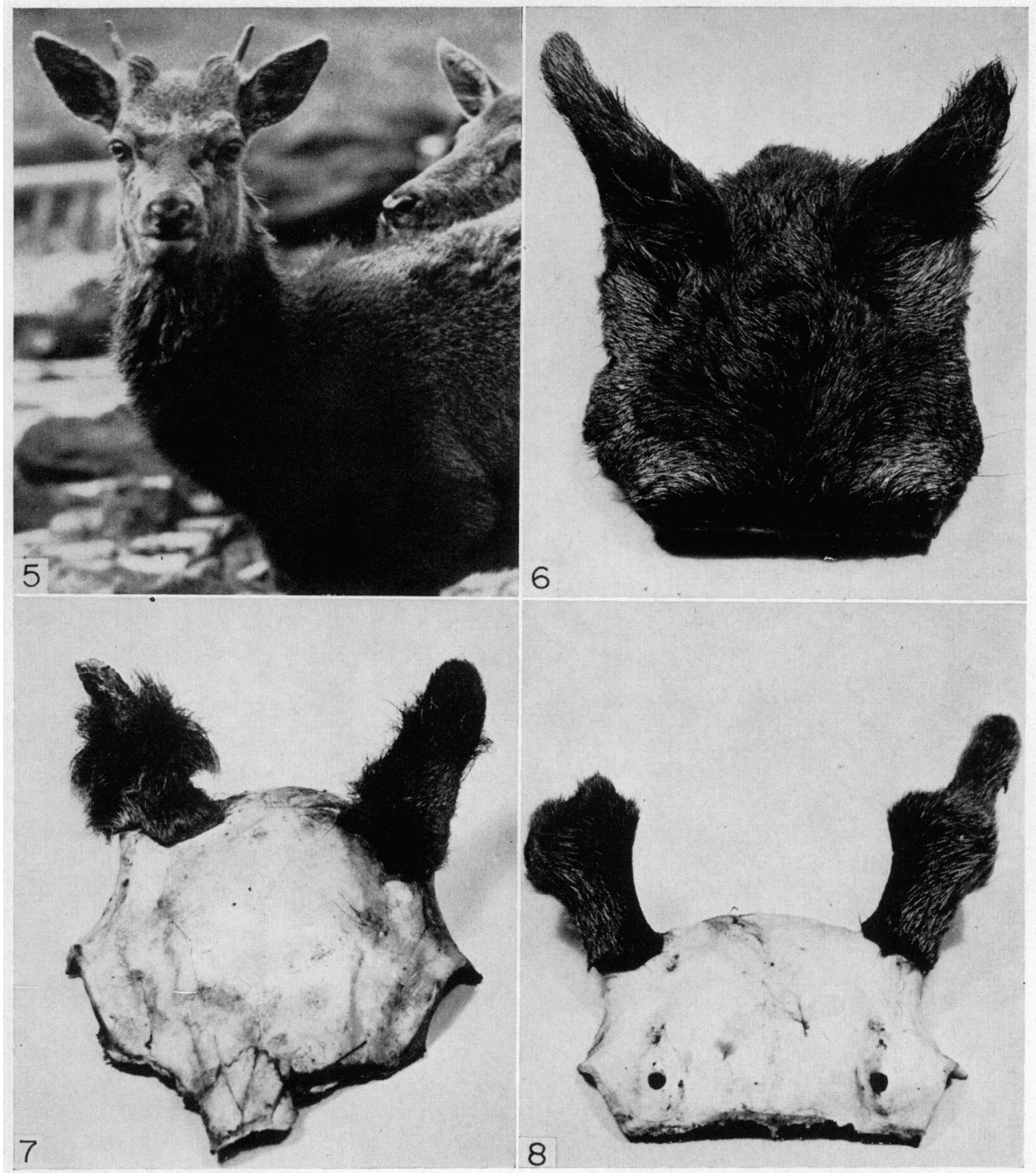

FIG. 5. A 22-month-old stag (15/4/70) living with its mother in a family group, and showing the spiky antlers and short neck mane, typical of a yearling.

Fig. 6. The skull cap of an 18-month-old stag (16/12/68) with fully developed pedicles, and antlers still in velvet 4 months after the mature stags have 'cleaned'.

Fig. 7. The skull cap of a 23 -month-old stag $(24 / 5 / 68)$ with one antler in hard horn and the other in velvet. The testes and accessory glands of this stag were fully regressed.

FIG. 8. The skull cap of a 2 -year-old stag (14/6/68) showing the second set of antlers just beginning to sprout from the pedicles. 
mirror that of testosterone at a much lower level (Text-fig. 3). At no stage was androstenedione more abundant than testosterone.

Changes in the accessory glands during the first 3 years of life

The epididymides, seminal vesicles, ampullae, prostate and pelvic urethra all

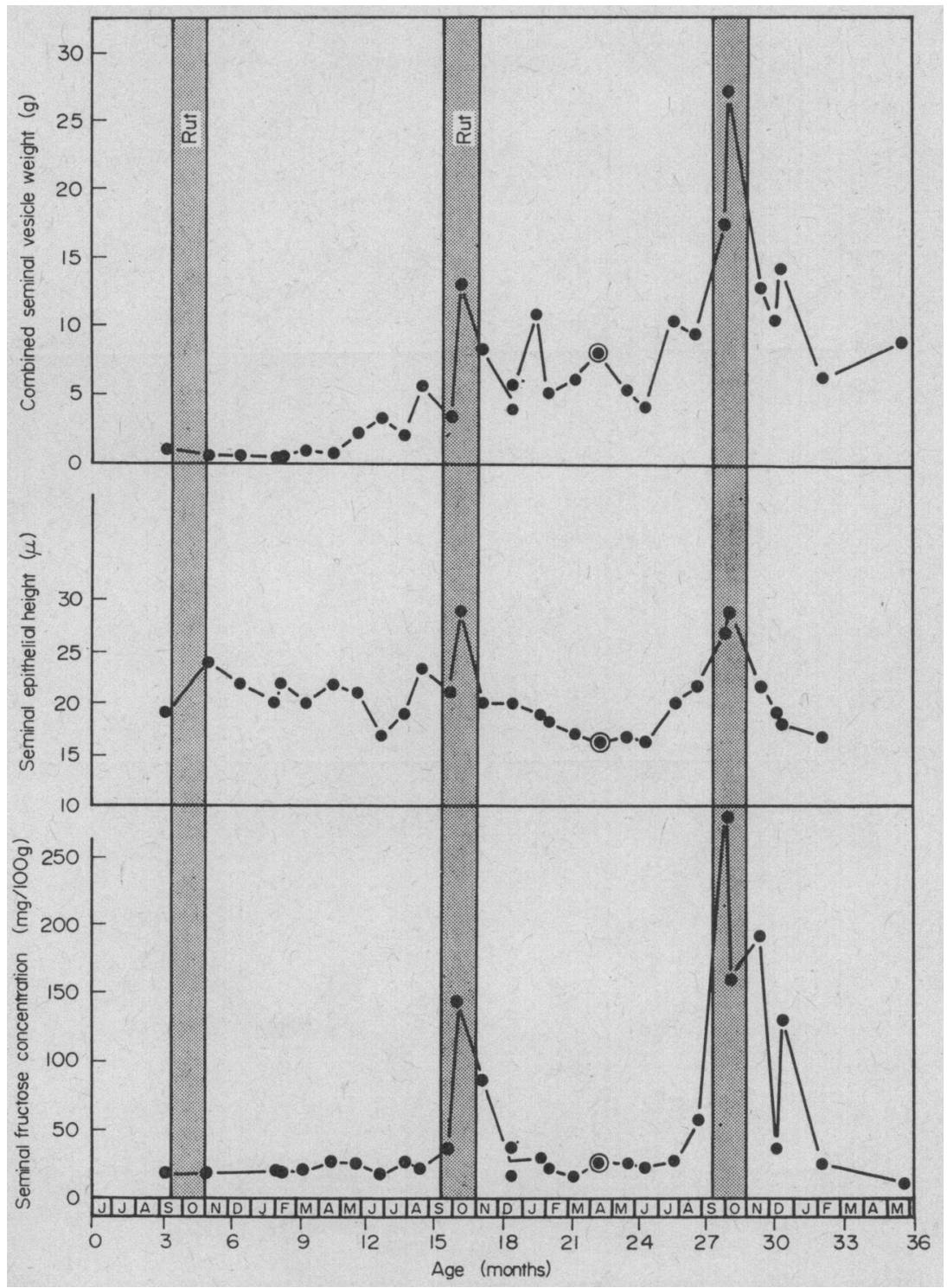

Texr-FIG. 5. The changes in the weight, epithelial height and fructose concentration of the seminal vesicles of stags during the first 3 years of life. For explanation of the encircled symbol see Text-fig. 2.

showed changes related to the development and regression of the testis (Textfigs. 4,5 and 6 ). The epididymis was the first of these accessory glands to begin development in the calf; at 9 months of age, coincident with the onset of 
androgenesis in the testis, there was an increase in the epithelial height and tubular diameter particularly in the peripheral zones of the cauda epididymidis. Two months later, in May, all the accessory glands had increased in weight and during the ensuing months they grew rapidly. The fructose concentration in the

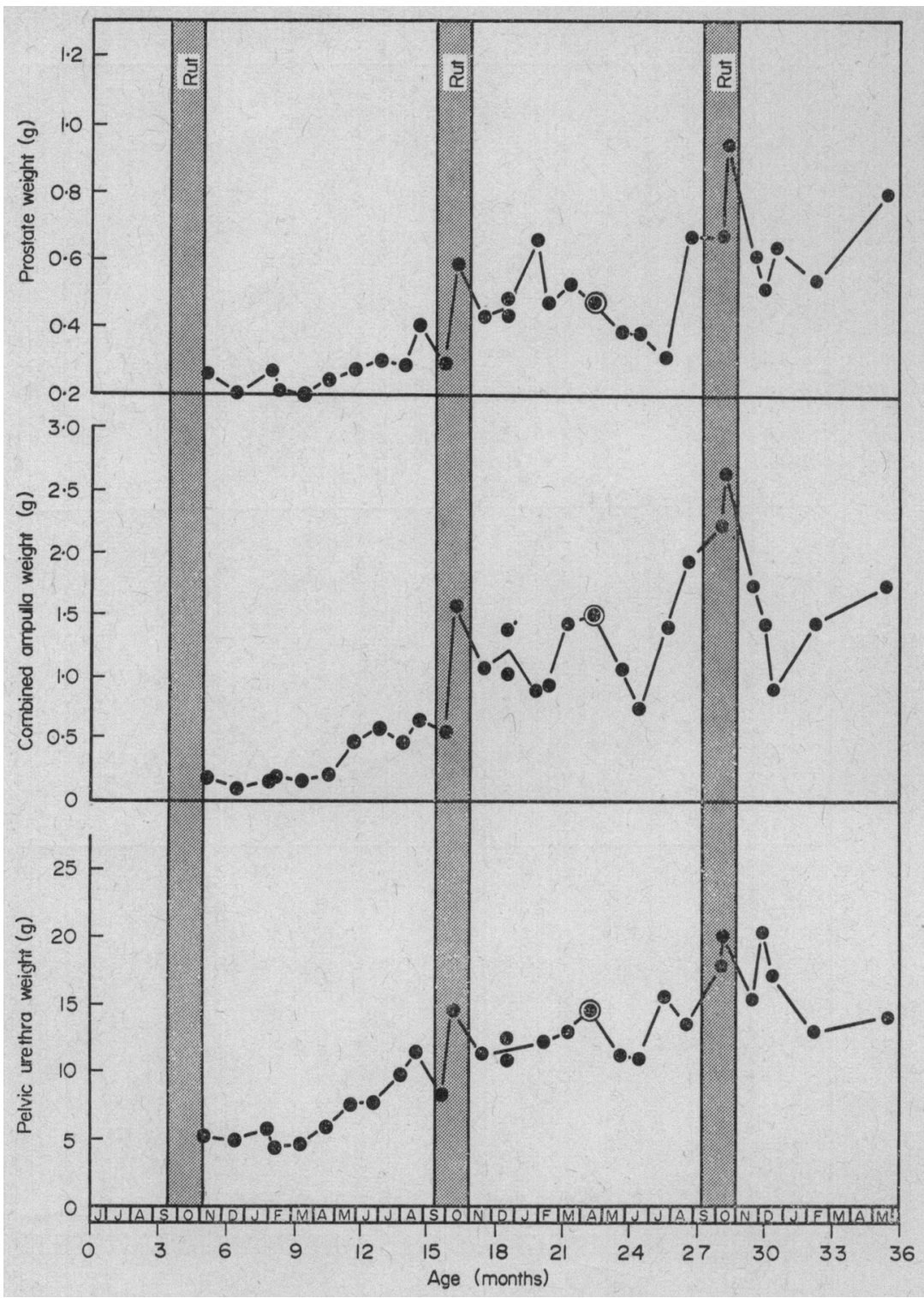

TEXT-FIG. 6. The changes in the weight of prostate, ampullae and pelvic urethra of stags during the first 3 years of life. For explanation of the encircled symbol see Text-fig. 2 .

seminal vesicles showed a pronounced increase in August, and all the accessory glands reached maximal development in October, when the testosterone content of the testis was also at a peak.

From November until June, the accessory glands tended to decline in weight 
and activity, although there was considerable variation between individuals which was not apparently related to the testosterone content of the testis. The seminal vesicles of the yearlings contained small amounts of free secretion from October until December, and the fructose concentrations were reduced to baseline levels by January. The caudal tubules of the epididymis were packed with spermatozoa from October to May. Although the accessory glands had completely regressed in June at 2 years of age, the weight of the glands remained well above the prepubertal figures.

In July and August, the accessory glands began to expand and were again maximally developed in October.

Changes in the secondary sexual characters during the first 3 years of life

Antlers. Small pedicle rudiments could be felt on the frontal bone at 3 months of age, but no pedicle growth occurred until the calf was nearly a year old. In May, at 11 months of age, the rudiments had expanded (see Text-fig. 3), and by August the pedicles were outwardly visible as knobs on the forehead. From October until December, antler tissue grew from the pedicles to form 2- to 5-cm spikes (Pl. 2, Fig. 6).

The youngest stag with antlers cleaned of velvet was shot at 19 months of age, in January, and the yearlings were in hard horn until May (Pl. 2, Fig. 5). One yearling shot in May was of particular interest as it had one antler in hard horn while the other was in velvet (Pl. 2, Fig. 7). By the end of June, at 2 years of age, the first set of antlers had been cast (Pl. 2, Fig. 8), and a new set grew in velvet until September. The velvet was then cleaned from the antlers before the adult stags began rutting in October, 3 months earlier than in the first cycle. The 2-year-olds remained in hard horn until the following May.

Neck mane and stag winter coat. During the 1st year of life, the stag calf did not develop the conspicuous neck mane and coarse, brown, winter coat of the adult. Instead, the calf completed an autumn moult in November, when 5 months old, and its winter coat more closely resembled that of a hind. The neck hair of this coat grew $(6 \mathrm{~cm})$ until December or January, but did not develop as a mane. The winter coat was shed in May and June at 1 year of age, at the same time as the adult stags and hinds. Initially, the new summer coat had shorter neck hairs ( 2 to $3 \mathrm{~cm}$ ) but by August, this was longer, and by mid-September, neck hair up to $7 \mathrm{~cm}$ long had grown through the summer coat.

In October, the yearling stag showed a conspicuous moult of the summer coat, again at the same time as moulting occurred in the hind. The neck mane continued to grow until January, by which time it was quite conspicuous (11 to $12 \mathrm{~cm}$ ). During November and December, as the mane was growing, the rest of the animal's coat acquired for the first time the coarse, brown appearance typical of the winter coat of the adult stag.

The cycle of moulting and hair growth in the 2-year-old stags was similar to that in the yearlings, except that there was no conspicuous autumn moult of the summer coat. It appeared that the onset of development of the 'stag' winter coat was shifted forward in the year, and thus its growth obscured the moulting of the summer coat. In these 2-year-olds, a conspicuous neck mane developed $(11$ to $14 \mathrm{~cm})$ from August until December. 
Neck girth. The neck girth of the young stags varied in relation to the reproductive cycle. From 3 to 15 months of age, the neck girth increased only slightly $(28$ to $34 \mathrm{~cm})$. However, in October, the girth expanded considerably to $41 \mathrm{~cm}$ in the yearling, and increased further in November to $46 \mathrm{~cm}$. Following this peak, the girth tended to decrease through the winter and spring, to become minimal $(32 \mathrm{~cm})$ in June and July at 2 years old. In the second cycle, the neck girth started to expand in August, reached a maximum $(43 \mathrm{~cm})$ in October, and was still quite enlarged in November and December.

Rutting odour and development of the voice. These two secondary sexual characters are particularly closely related to actual rutting behaviour and as the juvenile stags, though fertile, do not really rut, these features are poorly developed during the first 3 years of life. In the yearlings, there was barely any detectable rutting odour produced in relation to the first reproductive cycle, except in one of the

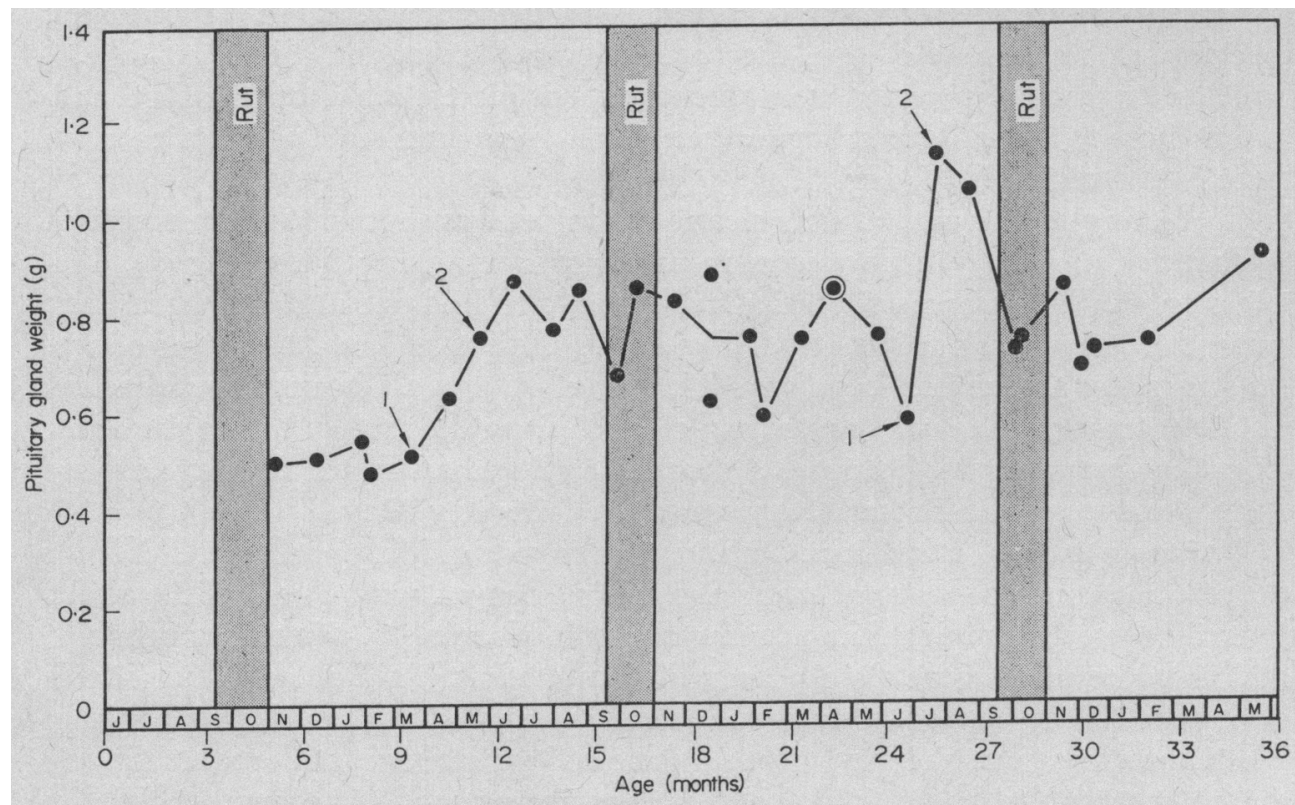

TEXT-FIG. 7. The changes in the weight of the pituitary gland of stags during the first 3 years of life. $1=$ onset of androgenesis in the testis; $2=$ onset of spermatogenesis in the testis. For explanation of the encircled symbol see Text-fig. 2.

December stags. The youngest animal to have distinctive rutting odour was a 2-year-old stag shot in October. This animal showed slight staining round the urethral orifice. In November, the rutting smell of the 2-year-olds was more conspicuous and the urine definitely contained the odour. By December, it was less evident and it had disappeared by February.

Incidental observations indicated that the yearlings did not roar at the height of testis activity in the first cycle. Occasionally, a 2-year-old, and more frequently a 3-year-old, was heard roaring between late October and December. These young animals had a characteristic high-pitched voice, compared to the deep, menacing roar of the adult.

Changes in the pituitary gland weight over the first 3 years of life. Up to 9 months of age, the weight of the pituitary gland was fairly constant (Text-fig. 7). In April 
and May, coincident with the beginning of testicular activity, the gland began to grow rapidly. By June, the pituitary weight had doubled, and was generally maintained at this level until November, when it began to decline, reaching a minimum by the following June at 2 years of age. With the resumption of spermatogenesis in July, the pituitary again increased in weight and reached a maximum in August and then tended to decline.

\section{DISCUSSION}

In the past, puberty in the male has been related both to the spermatogenic and to the androgenic functions of the testis. Asdell (1946) defined puberty as that time when the animal first becomes capable of reproduction, i.e. the time of the first appearance of spermatozoa. Alternatively, Marshall (1922) and more recently Donovan \& van der Werff ten Bosch (1965) related puberty to the time when the endocrine function of the testis first becomes clearly evident. The onset of androgenesis by the testis has been shown to precede spermatogenesis in several species including the rabbit (Davies \& Mann, 1947; Skinner, 1967), the stallion (Skinner \& Bowen, 1968), the bull (Mann, Davies \& Humphrey, 1949) and the ram (Skinner, Booth, Rowson \& Karg, 1968). Skinner (1967) concluded from his study of the rabbit that it was more accurate to relate the onset of puberty to the beginning of androgenesis than to spermatogenesis. If puberty in the stag were defined as a period rather than a point in time, puberty would be the time between the onset of androgenesis and the first appearance of spermatozoa in the testis, i.e. at 9 to 15 months of age.

Asdell (1946) drew a distinction between puberty and sexual maturity, the latter being the time when the animal assumes an effective rôle in the reproduction of the population. The separation between these two events is particularly striking in the red deer; at rutting time, each mature stag will try to collect together a harem of hinds and defend them against all rivals (Fraser Darling, 1937) and only those with the physical prowess to defeat their competitors will take an active part in the matings. Thus, on Rhum, the stag is fertile at $1 \frac{1}{2}$ years but not behaviourally mature until almost fully grown and at least 7 years old.

In a previous study, the seasonal reproductive changes in the adult red deer stag were described (Lincoln, 1971). From April until June, the adult stag is in a state of reproductive quiescence. There are very low levels of testosterone in the testes, no spermatogenesis and the accessory glands are involuted. At the end of June, the testosterone secretion progressively increases to reach a peak in October, and the accessory glands and secondary sexual characteristics redevelop before the start of the breeding season. Spermatogenesis is also resumed and spermatozoa appear in the epididymis in large quantities in August. Each year, therefore, the adult stag undergoes reproductive changes which resemble pubescence. From the present study, it is clear that the only way in which this recurrent seasonal puberty differs from the initial puberty is that some secondary sexual characteristics, like the antler pedicle, once formed during the first puberty, are established for life, and cannot regress like the accessory glands.

The age of the stag has a considerable influence on the timing of the various 
reproductive changes. The most conspicuous age effect involves the antler cycle; the yearling stag cleans the velvet from its antlers in November or December and casts them in June. As the stag grows older, the cycle is gradually shifted forward in the year, so that mature stags clean in early August and cast in late March and early April. A similar age effect is apparent in the timing of the development of the stag's other secondary sexual characters and in its rutting behaviour; the mature stags start the rut in mid-September, the 4- and 5 -year-olds are most active in late October and November, and the 2- and 3-year-olds show some interest in the hinds as late as December. The duration of spermatogenesis is likewise prolonged in the younger animals which may retain fertility until June, 2 months later than the adults. The seasonal changes in the accessory glands, however, do not show any such age shift and the seminal

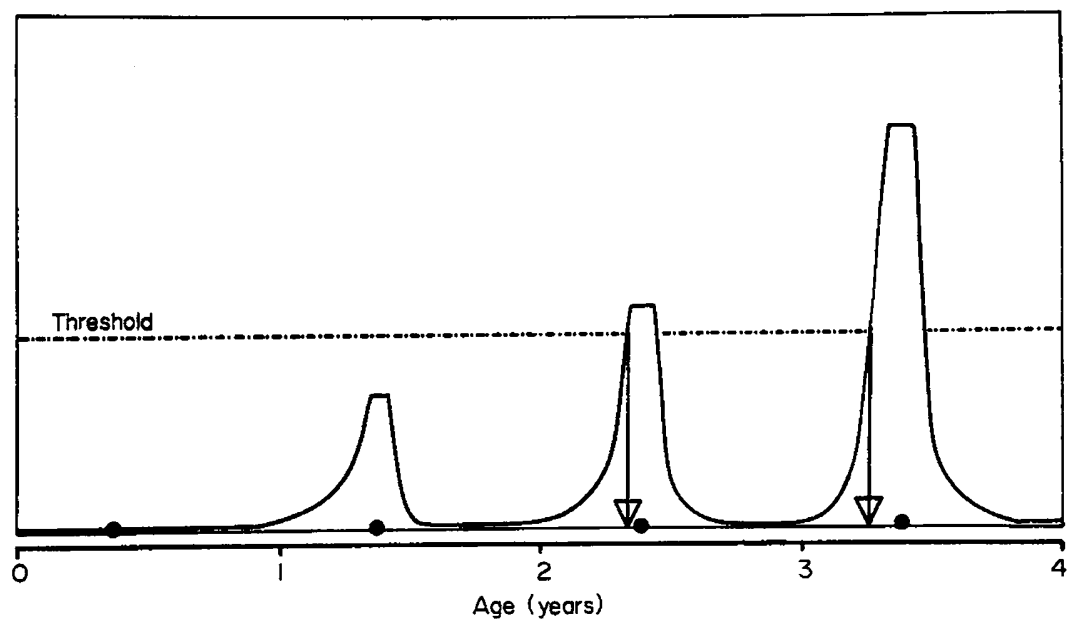

TEXT-FIG. 8. Diagram of the first three testosterone cycles in the life of the stag with the peak of secretion in October in each year, showing theoretically how a progressive increase in secretion during each cycle can lead to the 'age-shift' seen in the time of development of the secondary sexual characters, and rutting behaviour while the response threshold remains unchanged. $\bullet$, Middle of October.

vesicles, for example, are always maximally developed in October. Testosterone secretion actually begins earlier in the yearling than the adults and the peak androgenic activity occurs in October in all age classes.

A possible explanation for this delay in development of the secondary sexual characters may be in terms of a threshold response. Text-figure 8 represents diagrammatically the first three testosterone cycles in the life of the stag with the peak secretion in October of each year, showing how an increase in the magnitude of the androgen secretion with age can lead to the 'age-shift' while the response threshold remains unchanged. The secondary sexual characters and behaviour appear to respond to testosterone at a higher threshold than do the accessory glands. The effect of age on the time of rutting may have considerable importance in the breeding biology of the stag. It would appear to be advantageous for the young animals to begin rutting later in the year so they may 
move in and replace the exhausted master stags. This would avoid unnecessary conflict between widely separated age classes and would ensure maximal effective competition over the hinds.

Although this threshold theory explains the delayed sexual cycle of the young stag, the relationship between the hormone level and the antler cycle in the yearling stag requires further consideration. Experiments by Wislocki, Aub \& Waldo (1947) and Goss (1963) have shown that it is a rising level of testosterone which causes the shedding of the antler velvet, while the falling secretion leads to antler casting. This control mechanism fits well for the antler cycle in the adult stag (Lincoln, 1971) and in the present study for the 2-year-olds. In the yearlings, however, the relationship is obscure for antler cleaning occurs up to 2 months after the peak testosterone secretion, at a time when the hormone is practically undetectable. Possibly the cleaning process is a lengthy one and, once influenced by increased testosterone, is completed independently of the hormone. The second irregularity is that four of the yearlings which were nowhere near casting, had practically undetectable levels of testosterone in their testes. Presumably, in these animals, antler casting in June would not have been the result of decreasing androgen secretion. It is noteworthy that in the yearling, the antler cycle appears to be more closely related to spermatogenesis than androgenesis, and it is only in this first reproductive cycle that the stag shows full spermatogenesis while the antlers are still in velvet.

Observations based on the pedicle development of young stags would suggest that the age of puberty is greatly influenced by the plane of nutrition available. Stag calves on Rhum, when given supplementary feeding during the winter months, have developed pedicles several months in advance of the animals in the wild; stags living in favourable forest conditions and in deer parks may show pedicle growth as early as 3 months of age. At the other extreme, some deer on the Scottish mainland living under severe conditions, may not produce pedicles until they are 2 or 3 years old. It would seem that the year in which puberty occurs is controlled by the plane of nutrition and the time of year by some other factor such as photoperiod.

Puberty represents the first of the seasonal cycles of testicular activity in the life of the stag and, as in the subsequent cycles, development reaches a peak in the autumn. The photoperiodic control which limits the time of puberty appears to be basically similar to that which governs the seasonal cycle of the adult stag (Lincoln, Youngson \& Short, 1970). However, the young animals are able to commence testicular activity as early as March under conditions of increasing day-length, 3 months in advance of the older stags.

Goss (1969) found that Sika deer calves (Cervus nippon) could produce pedicles and develop their first antlers under a constant light regimen of equal light/dark periods. These yearlings then retained their antlers indefinitely, but castration of one of them led to antler casting. Thus, under suitable constant lighting conditions, these stags underwent a normal puberty, but thereafter the testis remained continuously active and failed to show the cyclical changes typical of a seasonal breeder. It seems possible that seasonally breeding animals like the stag are basically continuous breeders whose reproductive processes are actively suppressed for part of the year. 


\section{ACKNOWLEDGMENTS}

This study was supported by a Natural Environmental Research Gouncil grant. I am indebted to the Nature Conservancy for providing facilities on the Isle of Rhum Nature Reserve, and for arranging the cull of stags as required. I would like to thank in particular the Wardens, Mr P. Wormell and Mr G. MacNaughton, and the stalkers, Mr G. Sturton and Mr P. McRae. Dr R. V. Short kindly made many valuable suggestions throughout the project.

\section{REFERENCES}

Aspell, S. A. (1946) Patterns of mammalian reproduction. Comstock, Ithaca, New York.

Davies, D. V. \& MaNN, T. (1947) Functional development of accessory glands and spermatogenesis. Nature, Lond. 160, 295.

Donovan, B. T. \& van der Werff Ten Bosch, J. J. (1965) Physiology of puberty. Edward Arnold, London.

Fraser Darling, F. (1937) $A$ herd of red deer. Oxford University Press.

Goss, R. J. (1963) The deciduous nature of deer antlers. In: Mechanisms of Hard Tissue Destruction, pp. 339-369. Publication No. 75, Am. Ass. Adv. Sci., Washington, D.C.

Goss, R. J. (1969) Photoperiodic control of antler cycles in deer. I. Phase shift and frequency changes. F. $\exp$. Zool. 170, 311.

Lincoln, G. A. (1971) The seasonal reproductive changes in the adult red deer stag (Cervus elaphus L.). 7. Zool., Lond. (In press).

Lincoln, G. A., Youngson, R. W. \& Short, R. V. (1970) Social and sexual behaviour of the red deer stag. F. Reprod. Fert., Suppl. 11, 71.

LINDNER, H. R. \& MANN, T. (1960) Relationship between the content of androgenic steroids in the testis and the secretory activity of the seminal vesicles in the bull. 7. Endocr. 21, 341.

Lowe, V. P. W. (1967) Teeth as indicators of age, with special reference to red deer of known age from Rhum. F. Zool., Lond. 152, 137.

Mann, T., Davies, D. V. \& Humphrey, G. F. (1949) Fructose and citric acid assay in the secretions of the accessory glands of reproduction as indicator tests of male sex hormone activity. $\mathcal{F}$. Endocr. $6,75$.

Mann, T., Rowson, L. E. A., Short, R. V. \& Skinner, J. D. (1967) The relationship between nutrition and androgenic activity in pubescent twin calves, and the effect of orchitis. 7. Endocr. 38, 455.

Marshall, F. H. A. (1922) The physiology of reproduction, 2nd edn. Longmans Green, London.

Skinner, J. D. (1967) Puberty in the male rabbit. F. Reprod. Fert. 14, 151.

Sxinner, J. D., Booth, W. D., Rowson, L. E. A. \& KARG, H. (1968) The post-natal development of the reproductive tract of the Suffolk ram, and changes in the gonadotrophin content of the pituitary. 7. Reprod. Fert. 16, 463.

Skinner, J. D. \& Bowen, J. (1968) Puberty in the Welsh stallion. F. Reprod. Fert. 16, 133.

WislockI, G. B., AUB, J. G. \& WALDO, C. M. (1947) The effects of gonadectomy and the administration of testosterone propionate on the growth of antlers in male and female deer. Endocrinology, 40, 202. 